\title{
Toward finding the difference
} between untreated celiac disease and COVID-19 infected patients in terms of CD4, CD25 (IL-2 $\mathrm{Ra})$, FOXP3 and IL- 6 expressions as genes affecting immune homeostasis

Nastaran Asri ${ }^{1}$, Ehsan Nazemalhosseini Mojarad ${ }^{1}$, Hamed Mirjalalii ${ }^{2}$, Seyed Reza Mohebbi ${ }^{3}$, Kaveh Baghaei ${ }^{3}$, Mohammad Rostami-Nejad ${ }^{3 *}$ (D), Abbas Yadegar ${ }^{2}$, Mostafa Rezaei-Tavirani ${ }^{4}$, Hamid Asadzadeh Aghdaei ${ }^{3}$, Kamran Rostami ${ }^{5}$ and Andrea Masotti ${ }^{6}$

\begin{abstract}
Background: Coronavirus disease 2019 (COVID-19) is defined as an emerging infectious disease caused by severe acute respiratory syndrome coronavirus 2 and celiac disease (CD) is one of the autoimmune multiorgan diseases, which can be accompanied by an increased risk of viral infections. CD patients, especially untreated subjects, may be at greater risk of infections such as viral illnesses. Interleukin (IL)-6, CD4, CD25, and FOXP3 are known as genes affecting immune homeostasis and relate to the inflammation state. This study aimed to compare the expression levels of aforementioned genes in peripheral blood samples of CD and severe COVID-19 patients.
\end{abstract}

Methods: Sixty newly diagnosed CD patients with median age (mean \pm SD) of $35.40 \pm 24.12$ years; thirty confirmed severe COVID-19 patients with median age (mean \pm SD) of $59.67 \pm 17.22$, and 60 healthy subjects with median age (mean \pm SD) of $35.6 \pm 13.02$ years; were recruited from March to September 2020. Fresh whole blood samples were collected, total RNA was obtained and CDNA synthesis was carried out. RNA expression levels of IL-6, CD4, CD25, and FOXP3 genes were assessed using real-time quantitative RT-PCR according to the $2^{-\Delta \Delta C t}$ formula. Statistical analysis was performed using SPSS (V.21) and GraphPad, Prism (V.6).

Results: While increased expression of CD4, CD25, and FOXP3 was observed in CD patients compared to the control group ( $p=0.02, p=0.03$, and $p<0.0001$ respectively) and COVID-19 patients group ( $p<0.0001$ for all of them), their expression levels in COVID-19 patients decreased compared to controls ( $p<0.0001, p=0.01, p=0.007$, respectively). Increased IL-6 expression was observed in both groups of patients compared to controls ( $p<0.0001$ for both of them).

Conclusions: Although untreated CD patients may be at greater risk of developing into severe COVID-19 if they are infected by SARS-CoV-2 virus (due to their high expression of IL-6), increased expression of anti-inflammatory markers

\footnotetext{
*Correspondence: m.rostamii@gmail.com

${ }^{3}$ Gastroenterology and Liver Diseases Research Center, Research Institute

for Gastroenterology and Liver Diseases, Shahid Beheshti University

of Medical Sciences, Tehran, Iran

Full list of author information is available at the end of the article
}

(C) The Author(s) 2021. Open Access This article is licensed under a Creative Commons Attribution 4.0 International License, which permits use, sharing, adaptation, distribution and reproduction in any medium or format, as long as you give appropriate credit to the original author(s) and the source, provide a link to the Creative Commons licence, and indicate if changes were made. The images or other third party material in this article are included in the article's Creative Commons licence, unless indicated otherwise in a credit line to the material. If material is not included in the article's Creative Commons licence and your intended use is not permitted by statutory regulation or exceeds the permitted use, you will need to obtain permission directly from the copyright holder. To view a copy of this licence, visit http://creativecommons.org/licenses/by/4.0/. The Creative Commons Public Domain Dedication waiver (http://creativeco mmons.org/publicdomain/zero/1.0/) applies to the data made available in this article, unless otherwise stated in a credit line to the data. 
in these patients may be beneficial for them with the ability of reducing the severity of COVID-19 disease, which needs to be proven in future studies involving celiac patients infected with COVID-19.

Keywords: SARS-CoV-2, COVID-19, Celiac disease, Gene expression, T-Lymphocytes, Regulatory, Interleukin-6

\section{Background}

Celiac disease $(\mathrm{CD})$ is a global, chronic, immune-mediated gluten-sensitive enteropathy elicited by dietary gluten in genetically predisposed individuals [1]. CD can induce various gastrointestinal (i.e., diarrhea, bloating, and abdominal pain) and extra-intestinal (i.e., iron deficiency anemia, osteoporosis, and weight loss) manifestations, or it may not be accompanied by any symptoms [2]. Gluten consumption changes the pro- and anti-inflammatory states and rises the production of pro-inflammatory cytokines leading to small intestinal inflammation in CD patients, which involves both innate and adaptive immune responses [3].

Interleukin 6 (IL-6) is a pleiotropic cytokine produced by different cell types and has both pro- and anti-inflammatory effects [4]. IL- 6 , as a pro-inflammatory agent, can stimulate the synthesis of acute-phase reactant proteins, and its overproduction is associated with inflammatory autoimmune disorders and uncontrolled intestinal inflammation (which takes place in CD) [5-7]. Numerous studies have linked IL- 6 to the development of celiac disease [8].

Moreover, anti-inflammatory mediators, most importantly regulatory $\mathrm{T}$ cells (Tregs), can migrate into inflamed sites and attempt to minimize inflammatory responses [9]. The recruitment of Tregs is known as a key suppressive mechanism in maintaining peripheral immune homeostasis in chronic inflammatory diseases like CD [10].

Coronavirus disease 2019 (COVID-19) is defined as an emerging infectious disease caused by severe acute respiratory syndrome coronavirus 2 (SARS-CoV-2), which leads to a range of clinical manifestations including respiratory symptoms, fever, cough, kidney failure, or it can even be asymptomatic [11-13]. COVID-19 causes an ongoing global pandemic, as first identified in Wuhan, China, in December 2019 from a zoonotic source [1113]. In general, the pathogenicity of a virus is dependent upon interactions between the pathogen and host pro- and anti-inflammatory mediators [14]. The interplay between innate and adaptive immune responses is involved in the development of COVID-19 disease. In fact, COVID-19 has an inflammatory pathophysiology involving a cytokine storm and it has been reported that during this infection the level of various analytes can change [15]. The unpredictability of the clinical course of the disease reinforces the need to find biomarkers that can help identify patients who are more vulnerable to clinical deterioration and improve patients' management [16]. Previous studies investigated different biomarkers such as C-reactive protein (CRP), interleukin (IL)-6, procalcitonin (PCT), etc. in COVID-19 patients and their association with disease progression [15]. Among them IL-6 has attracted particular attention.

Several studies reported the significant role of IL-6 in the progression or suppression of viral infections [17]. Dysregulation of IL-6 was found to be related to the COVID-19 progression, and previous findings have reported its association with the severity of the disease, respiratory failure, and mortality in this group of patients $[6,18,19]$. In fact, the proper production of proinflammatory markers like IL- 6 by various cell types after SARS-CoV-2 infection is positive in resolving the viral infection, that happens as a result of bacterial infections self-limitation due to human immune responses [20].

Tregs are important factors in controlling inflammation and preventing tissue complications during acute viral infections [19]. Anghelina et al. [21] reported that depletion of Tregs by treatment with anti-CD25 mAb (mAb PC61) from mice infected with murine coronavirus (rJ.M $\mathrm{Y}_{\mathrm{Y} 135 \mathrm{Q}}$-infected mice) resulted in a higher mortality rate with acute encephalitis. It is worth noting that, an important reason why obesity is reported as an unfavorable prognostic marker for COVID-19 is due to a decreased number of Tregs in the circulation and visceral adipose tissues in obese subjects [22]. Tregs express numerous receptors and non-receptor molecules on their surface that can be used as hallmarks to identify these cells. These markers include CD4 (one of the first markers expressed by Tregs), CD25 (essential for Tregs differentiation), and Forkhead box P3 (FOXP3) transcription factor (required for Tregs development and suppressive activity) [23-26].

It is noteworthy that $\mathrm{CD}$ patients may be at greater risk of infections such as viral illnesses [27, 28]. Although the results of studies indicate that there is not any increased risk of severe COVID-19 infection in gluten-free diet treated CD patients, little is known about untreated subjects, which caused concern among this group of patients and health care system [29, 30]. Due to the important role of IL- 6 and Tregs in celiac disease and coronavirus infection, and owing to the importance of Treg markers in their development and activity, this study aimed to evaluate the gene expression of IL-6, CD4, CD25, and 
FOXP3 in peripheral blood samples of newly diagnosed CD patients and COVID-19 infected people, relative to healthy subjects, to compare their inflammation state. In fact, we conducted this study to compare the inflammatory status of active celiac patients with severe COVID19 infected subjects to evaluate if newly diagnosed or even undiagnosed $C D$ patients are at increased risk of severe COVID-19 infection.

\section{Methods}

\section{Clinical samples}

60 newly diagnosed $C D$ patients who were not infected with the COVID-19, median age (mean \pm SD) $35.40 \pm 24.12$ years; 23 males and 37 females, and 30 confirmed severe COVID-19 patients, median age $($ mean \pm SD) $59.67 \pm 17.22$ years; 20 males and 10 females, considered as patient groups. Patients were admitted to Taleghani hospital (Tehran, Iran) from March to September 2020. In addition, sixty healthy subjects, median age (mean \pm SD) $35.6 \pm 13.02$ years; 27 males and 33 females, with no history of $C D$ and other immune-related diseases who were not infected with COVID-19 and had no contact with infected people were used as controls.

The confirmed cases of COVID-19 (based on clinical manifestations, radiology/CT scan, molecular detection by qPCR), who were within a week of developing symptoms, and confirmed untreated CD patients (according to serological and histopathological (Marsh classification) criteria) [27], were included in this study. The following patients were excluded from the study: CD patients who had another autoimmune disorder, COVID-19 patients with any autoimmune disorder, and patients who used any prohibited medications. Healthy individuals who had not current or prior history of gastrointestinal disorders and COVID-19 infection, and females who were not pregnant were included. Fresh whole blood $(10 \mathrm{~mL}) \mathrm{sam}-$ ples were collected from patients belonging to the abovedescribed studied groups in EDTA anticoagulant tubes using standardized venipuncture.

\section{Ethics statement}

We obtained approval from the Ethics Committee of Shahid Beheshti University of Medical Sciences, Tehran, Iran (IR.SBMU.RETECH.REC.1399.088). Written informed consent was obtained from patients before they participated in the research.

\section{RNA extraction and CDNA synthesis}

Total RNA was obtained from peripheral blood mononuclear cells (PBMCs) using the Total RNA Purification Mini kit for Blood/Cultured Cell/Tissue (Yekta Tajhiz Azma, Tehran, Iran) according to the provided protocol.
Isolated RNA quantity and purity were determined by spectrometry (Nanodrop, Thermo Scientific NanoDrop Products, Wilmington, DE, USA) and gel electrophoresis. Seven micrograms of total RNA were used for cDNA synthesis using the 2 Step 2X RT-PCR Premix (Taq) kit (BioFact ${ }^{\mathrm{TM}}$, South Korea), according to the manufacturer instructions in total $20 \mu \mathrm{L}$ reaction mixture. RT reaction conditions were used: $25{ }^{\circ} \mathrm{C}$ for $5 \mathrm{~min}, 50{ }^{\circ} \mathrm{C}$ for $30 \mathrm{~min}$, and $95^{\circ} \mathrm{C}$ for $5 \mathrm{~min}$.

\section{Gene expression analysis}

Appropriate primers for IL-6, CD4, CD25, FOXP3, and Glyceraldehyde 3-phosphate dehydrogenase (GAPDH), as internal control, were designed and analyzed by Gene Runner v. 3.05 software (Table 1). In the following, the specificity of the primers was checked by performing PCR experiments. The reaction was immediately started by a denaturation step for $5 \mathrm{~min}$ at $95^{\circ} \mathrm{C}$, followed by 40 cycles of $40 \mathrm{~s}$ at $94{ }^{\circ} \mathrm{C}, 30 \mathrm{~s}$ at $57-62^{\circ} \mathrm{C}$ (Temperature gradient), and $30 \mathrm{~s}$ at $72{ }^{\circ} \mathrm{C}$, and a final extension step for $10 \mathrm{~min}$ at $72{ }^{\circ} \mathrm{C}$. Products were separated by electrophoresis on a $1.5 \%$ agarose gel, and bands were visualized using UV-fluorescence.

The messenger RNA (mRNA) expression of the target genes was determined using real-time quantitative RTPCR according to the $2^{-\Delta \Delta C t}$ formula $\left(\Delta \mathrm{Ct}=\mathrm{Ct}^{\text {gene }}-\mathrm{Ct}^{\mathrm{con}-}\right.$

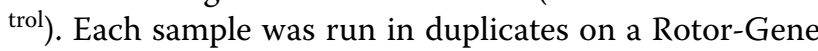
$\mathrm{Q}$ real-time PCR system (QIAGEN) using $10 \mu \mathrm{L}$ of $2 \mathrm{X}$ Real-Time PCR Smart mix Sybergreen (BioFact ${ }^{\mathrm{TM}}$, South Korea), $1 \mu \mathrm{L}$ cDNA, $0.5 \mu \mathrm{L}$ of each forward and reverse primers, and $8 \mu \mathrm{L}$ of $\mathrm{H} 2 \mathrm{O}$ in a final volume of $20 \mu \mathrm{L}$. The cycling program started with heating at $95^{\circ} \mathrm{C}$ for $15 \mathrm{~min}$ followed by 40 cycles of a three-stage temperature profile of $95^{\circ} \mathrm{C}$ for $10 \mathrm{~s}, 56^{\circ} \mathrm{C}\left(\mathrm{CD} 4\right.$ and IL-6) and $60{ }^{\circ} \mathrm{C}(\mathrm{CD} 25$

Table 1 Specific primers used for real-time quantitative PCR

\begin{tabular}{llll}
\hline Gene symbol & Primer sequence & Length & $\begin{array}{l}\text { Product } \\
\text { length } \\
\text { (bp) }\end{array}$ \\
\hline CD4 & F:5'-ACATCAAGGTTCTGCCCAC-3' & 19 & 190 \\
& R:5'-TGGCAGGTCTTCTTCTCAC-3' & 19 & \\
CD25 & F:5'-ACTTCCTGCCTCGTCACAAC-3' & 20 & 174 \\
& R:5'-ACTCTTCCTCTGTCTCCGCT-3 & 20 & \\
FOXP3 & F:5'-TCATCTGTGGCATCATCCG-3' & 19 & 167 \\
& R:5'-AGGAACTCTGGGAATGTGC-3' & 19 & \\
IL-6 & F:5'-GATTCAATGAGGAGACTT & 22 & 132 \\
& GCC-3' & & \\
& R:5'-GGTCAGGGGTGGTTATTGC-3' & 22 & \\
GAPDH & F:5'-TGTGGGCATCAATGGATT & 21 & 116 \\
& TGG-3' & & \\
& R:5'-ACACCATGTATTCCGGGT & 22 & \\
& CAAT-3' & &
\end{tabular}


and FOXP3) for $40 \mathrm{~s}$, and $72{ }^{\circ} \mathrm{C}$ for $30 \mathrm{~s}$. The workflow was controlled for contamination completely.

\section{Statistical analysis}

Statistical analysis was performed using SPSS (V.21) and GraphPad, Prism (V.6). The significance of differences in averaged gene expressions was analyzed using One-way ANOVA followed by the Tukey test. $p$ values $\leq 0.05$ were considered significant.

\section{Results}

\section{Clinical characteristics of study subjects}

Most of the COVID-19 patients presented with fever $(26 / 30,86.6 \%)$, dry cough $(23 / 30,76.6 \%)$, and fatigue (20/30, 66.6\%). The most common gastrointestinal symptoms of CD patients were bloating $(10 / 60,16.6 \%)$ and diarrhea $(9 / 60,15 \%)$, and the most common extra-gastrointestinal symptoms were fatigue $(13 / 60,21.6 \%)$ and anemia $(10 / 60,16.6 \%)$ (Fig. 1).

\section{Gene expression analysis}

The comparative threshold cycle $(\mathrm{Ct})$ method was used to determine relative transcript levels of $\mathrm{CD} 4$, CD25, FOXP3, and IL-6 genes using GAPDH as a housekeeping control. The results showed that the relative expression levels of CD4, CD25, and FOXP3 mRNA were significantly increased in $C D$ patients (mean \pm SD: $\quad 1.05 \pm 0.45, \quad 0.75 \pm 0.39, \quad 1.96 \pm 0.99$, respectively) compared to the control group (mean \pm SD: $\quad 0.86 \pm 0.37, \quad 0.58 \pm 0.37, \quad 0.87 \pm 0.75$, respectively), ( $p=0.02, p=0.03$, and $p<0.0001$ respectively) and COVID-19 patients' group (mean \pm SD: $0.18 \pm 0.25, \quad 0.32 \pm 0.33, \quad 0.33 \pm 0.27, \quad$ respectively),

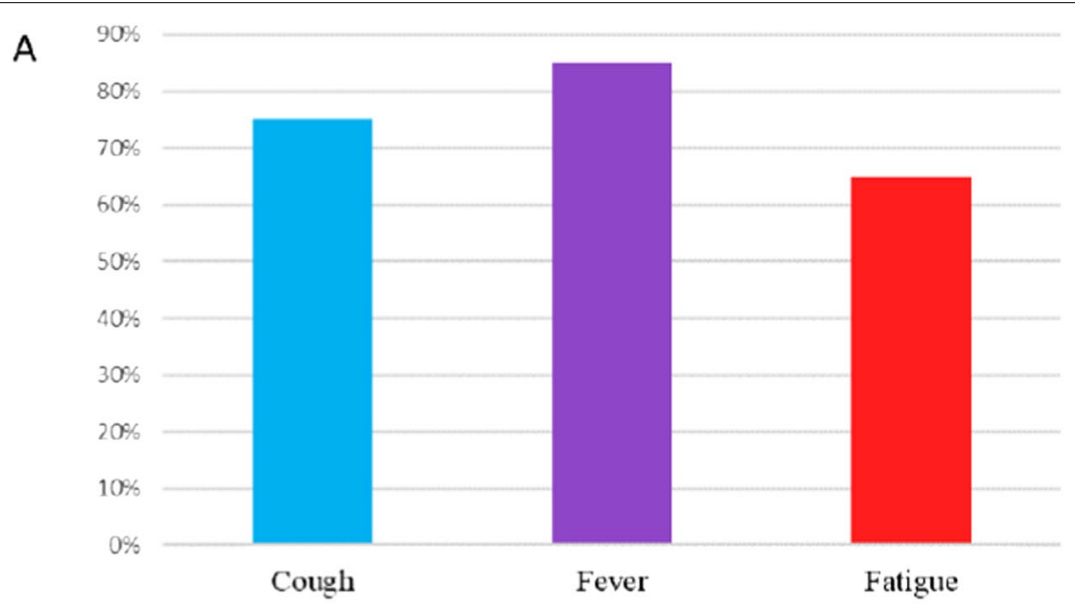

B

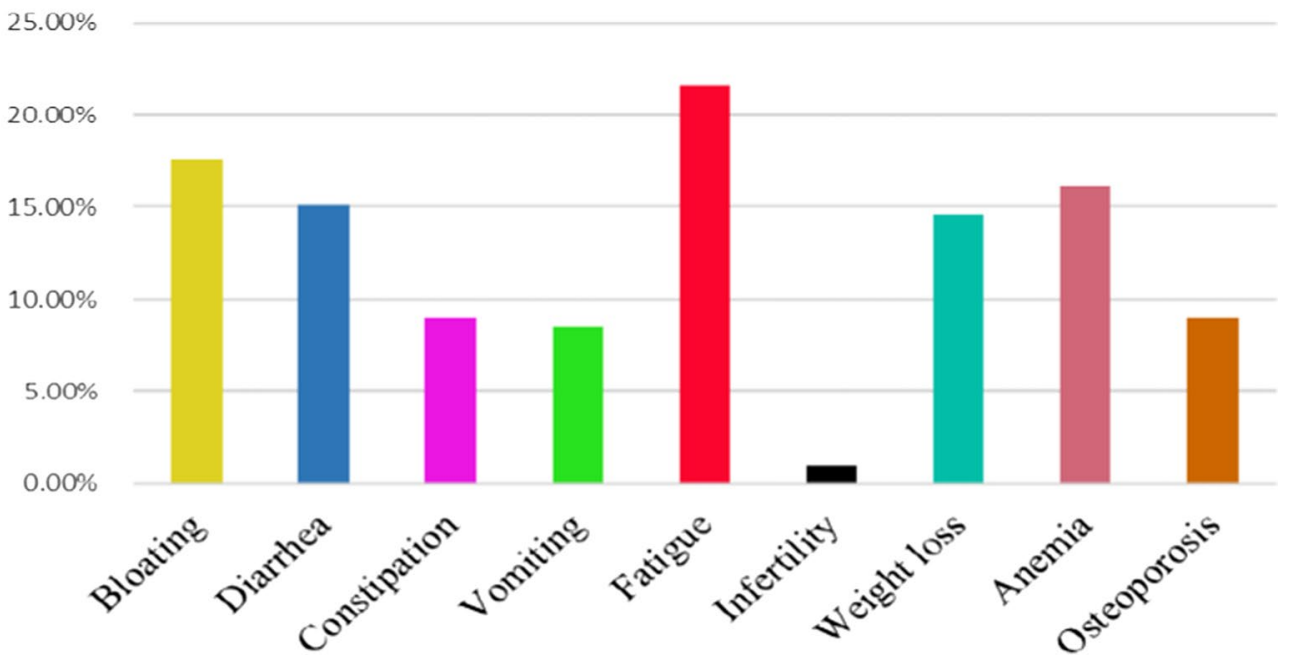

Fig. 1 Symptoms reported by COVID-19 and CD patients: most patients complained of two or more symptoms. A COVID-19 patients, B CD patients symptoms. COVID-19 Coronavirus disease 2019, CD celiac disease 
$(p<0.0001$ for all of them). On the contrary, the relative level of CD4, CD25 and FOXP3 mRNA expression in COVID-19 patients was significantly lower than in controls $(p<0.0001, p=0.01, p=0.007$, respectively) (Fig. 2). Moreover, the expression level of IL-6 exhibited a significant increase in both $C D$ (mean \pm SD: $19.16 \pm 8.11$ ) and COVID-19 patients (mean \pm SD: $15.42 \pm 11.23)$ in comparison to controls (mean $\pm S D$ : $2.81 \pm 1.02),(p<0.0001$ for both of them), but there was no significant difference in IL-6 level between these two groups of patients (Fig. 2).

\section{Discussion}

COVID-19 is a viral disease that may trigger an inflammation similar to $C D$ and is associated with impaired immune tolerance [31-33]. Celiac disease is one of the autoimmune multiorgan diseases, which can be accompanied by an increased risk of viral infections [27]. While preliminary results suggest that GFD-treated CD patients are less likely to develop severe COVID-19 infection, it has been reported that their defective nutritional status (Folate, vitamin $B_{12}$ and vitamin $D$ ), specially in those who are not treated with GFD, is associated with a higher risk of respiratory infections $[29,34]$. Likewise, limited
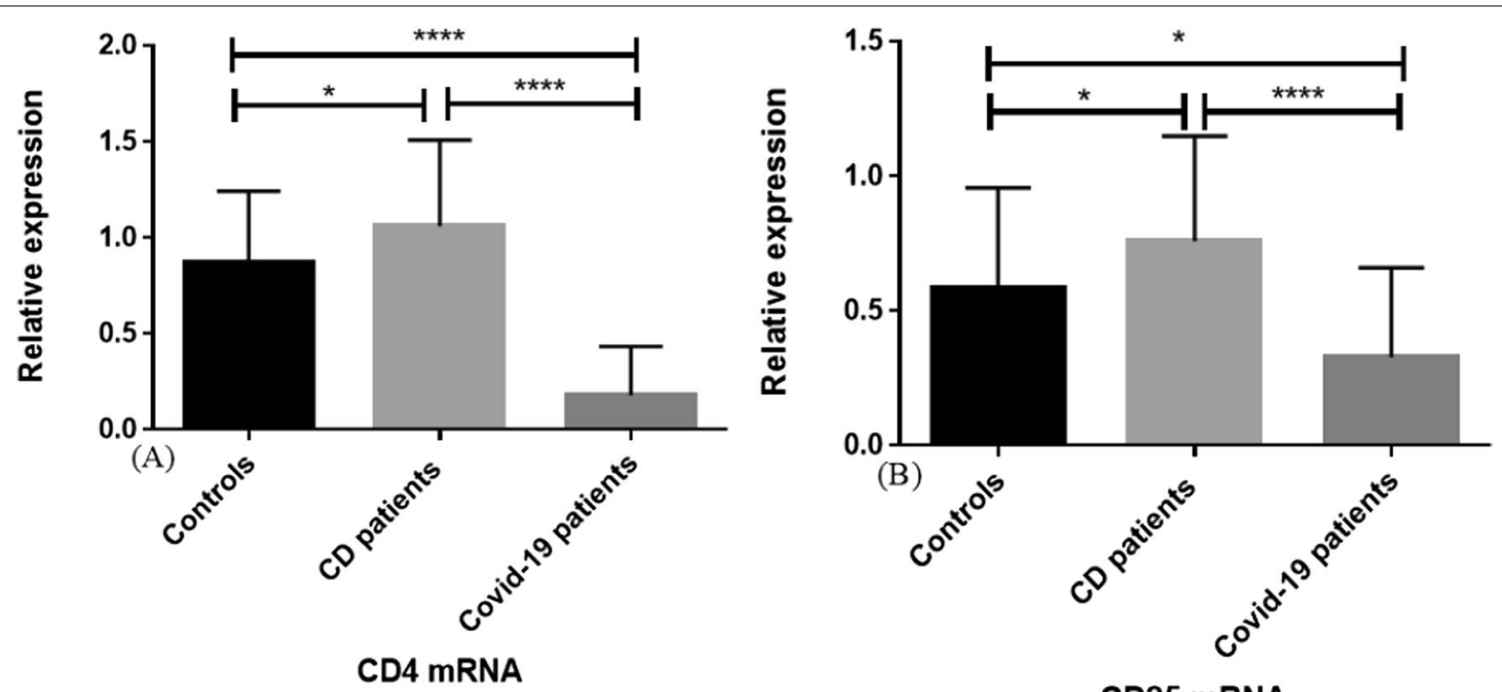

(B)
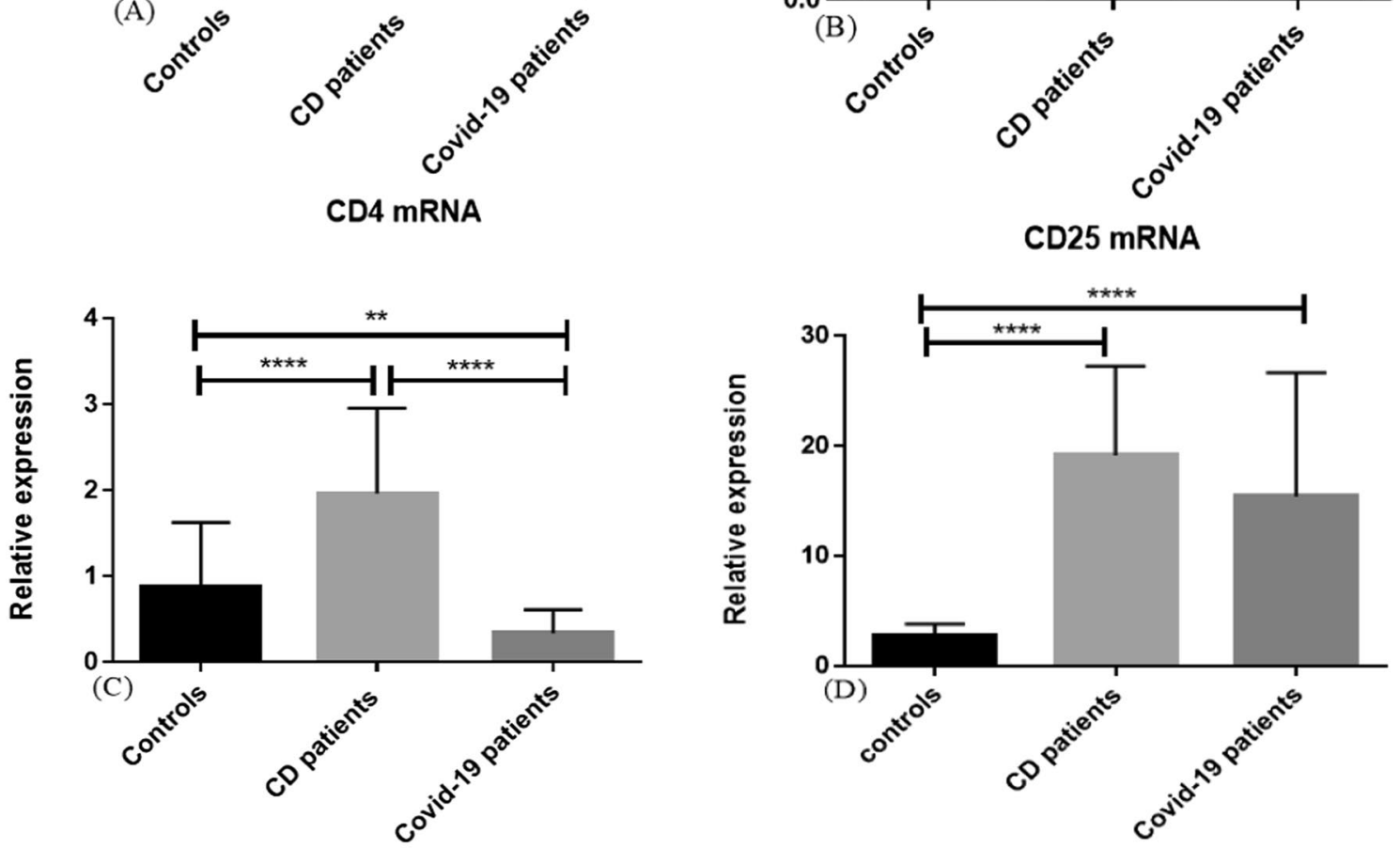

FoxP3 mRNA

IL-6 mRNA

Fig. 2 Analysis of relative expression levels in CD and COVID-19 patients compared to normal controls using real-time PCR assay. All expression levels are normalized to that of GAPDH. The analysed genes were as follows: A CD4; ${ }^{*} p=0.02,{ }^{* * * *} p<0.0001, \mathbf{B}$ CD25; ${ }^{*} p=0.01$ (between COVID-19 patients and controls) and $p=0.03$ (between CD patients and controls), ${ }^{* * *} p<0.0001 ;$ C FOXP3; ${ }^{* *} p=0.007,{ }^{* * * *} p<0.0001 ; \mathbf{D} \mid \mathrm{L}-6 ;{ }^{* * * *} p<0.0001$. Data are presented as mean \pm S.D. CD celiac disease, COVID-19 coronavirus disease 2019, GAPDH glyceraldehyde 3-phosphate dehydrogenase, FOXP3 forkhead box P3 
data are available on the risk of severe COVID-19 infection in untreated celiac disease patients [29].

IL-6, as a pro-inflammatory cytokine, is involved in inflammation and can adversely affect immune responses against virus infection [35-37]. Present data showed that the expression level of IL-6 is significantly increased in the PBMC of both severe COVID-19 and CD patients in comparison to controls ( $p<0.0001$ for both of them). In this regard, in a meta-analysis study conducted on a total of 1426 COVID-19 patients it has been demonstrated that, mean IL- 6 levels were extremely higher in complicated COVID-19 patients in comparison to those with non-complicated disease [38]. Studies considered this cytokine as a potential predictor of COVID-19 severity, respiratory failure and mortality risk $[19,39,40]$. In celiac disease, IL-6 stimulates acute phase responses and promotes T-helper cell 17 (Th17) differentiation, which leads to tissue injury [41]. Studies showed an increase in serum levels of IL-6 in untreated CD patients following gluten intake and its decrease after one-year gluten elimination from the diet [5]. Accordingly, Romero-Adrián et al. demonstrated an appropriate correlation between IL- 6 and CD activity and found it as a suitable marker for detecting minimal contamination with gluten-containing substances [42]. Noting that the patients in this study were also in the active phase of the disease, the increase in IL-6 levels is reasonable. In fact, the overproduction of pro-inflammatory cytokines like IL-6 is associated with autoimmune disorder, and lead to cytokine storm, what is reported in severe COVID-19 patients [43].

The expression levels of CD4, CD25 and FOXP3 showed a significant decrease in severe COVID-19 patients' PBMC compared to controls $(p<0.0001$, $p=0.01, \quad p=0.007$, respectively) and $\mathrm{CD}$ patients $(p<0.0001$ for all of them). Conversely, a significant increase in expression levels of these markers was shown in the $C D$ patients' $P B M C$ specimens related to healthy controls $(p=0.02, p=0.03$, and $p<0.0001$ respectively). These results complement data from previous studies [22]. Han and co-workers [44] showed increased peripheral blood CD4+ $\mathrm{T}$ cell numbers in $\mathrm{CD}$ patients who were on a gluten-free diet in response to oral gluten challenge. Vorobjova et al. [45] also reported that the majority of $C D$ patients' intestinal lymphocytes were $\mathrm{CD} 4$ cells. Considering that glutenspecific $\mathrm{CD} 4+\mathrm{T}$ cells also play a role in driving the pathogenic immune responses in $\mathrm{CD}, \mathrm{CD} 4$ increased expression may indicate both disease progression and suppression [10, 46]. Tiittanen et al. [47] observed an increased number of CD25+ cells in the intestinal specimens of children with active CD. Penttila and colleagues [48] also showed increased expression of IL-2R on PBMCs from CD patients in response to stimulation with gluten fraction. These results are in line with the finding of our study. Moreover, Frisullo et al. [49] reported increased expression of FOXP3 in peripheral blood CD4+ CD25+ T cells of untreated CD patients compared to treated patients. As FOXP3 expressing Tregs have an important role in maintaining the intestinal hemostasis balance, the increased FOXP3 gene expression by our CD patients makes sense [50,51].

Current reports on the number of Treg cells and their markers expression in COVID-19 patients remains controversial. Although plenty of studies indicate the increased Treg cells and markers in patients with COVID-19 (especially those with the milder disease), their significant reduction in PBMCs of severe COVID-19 patients was also reported in other studies [52]. Ong et al. [53] and Diao and colleagues [54] linked the decreased blood expression of CD4 in COVID-19 patients to severe form of the disease. Mohebbi et al. [55] demonstrated a downregulated PBMC expression level of CD4 and CD25 in COVID-19 patients in comparison to healthy controls that was in line with our results. It is important to note that CD25 deficiency is reported to be accompanied by increased susceptibility for chronic viral infections [56]. Decreased levels of FOXP3 mRNA and its association with increased IL-6 transcription level in COVID-19 infection, which was observed in our study, have also been reported by Mohebbi et al. [53]. In a recent study, decreased number of Tregs with a decreased expression of FoxP3 mRNA and immunosuppressive cytokines (IL10 and TGF $\beta$ ) was reported in PBMC derived from the COVID-19 patients treated in ICU [54]. Authors declared that, these reductions in severe cases of the COVID-19 may contribute to the excessive production of pro-inflammatory cytokines that leads to ARDS [50].

In case of $\mathrm{CD}$, as the pro-inflammatory markers like IL-6 are already present, the pre-existing autoimmune reaction may help to curb the proliferation of SARSCoV-2 virus when the $C D$ patients are contacted with the SARS-CoV-2 virus, makes the COVID-19 cases of CD patients to be mild if the CD patients do not have metabolic disorders like obesity or diabetes mellitus. Yet, the present of SARS-CoV-2 viral infection may further worsen the autoimmune disorder in $\mathrm{CD}$ patients [43]. In other words, it can be said that the high level of anti-inflammatory mediator markers observed in untreated patients with celiac disease, may prevent them from developing into severe COVID-19 if they are infected by SARS-CoV-2 virus. Further studies are needed to confirm or refute our hypothesis. 


\section{Conclusions}

The results of this study can provide clinically useful information about CD and COVID-19 infection patients' inflammation state. In our opinion, although high levels of IL-6 can be detrimental to untreated $\mathrm{CD}$ patients and predispose them to severe COVID19 infection if they are infected by SARS-CoV-2 virus, increased expression of CD4, CD25 and FOXP3 as antiinflammatory markers in these patients may be beneficial for them with the ability of reducing the severity of COVID-19 disease, which needs to be proven in future studies involving celiac patients infected with COVID19. The limitation of our study is not to include CD patients which tested positive for COVID-19 and therefore, further studies are needed to confirm/ reject the role of anti-inflammatory markers in protecting celiac patients from COVID-19 infection.

\begin{abstract}
Abbreviations
CD: Celiac disease; COVID-19: Coronavirus disease 2019; CT: Comparative threshold; FOXP3: Forkhead box P3; GAPDH: Glyceraldehyde 3-phosphate dehydrogenase; IL: Interleukin; mRNA: Messenger RNA; PBMCs: Peripheral blood mononuclear cells; SARS-CoV-2: Severe acute respiratory syndrome coronavirus 2; Th17:T-helper cell 17; Tregs: Regulatory T cells.
\end{abstract}

\section{Acknowledgements}

This study was supported by Shahid Beheshti University of Medical Sciences, Tehran, Iran. The authors would like to thanks Dr Robert Anderson from Wesley Medical Research - The Wesley Hospital, Brisbane, Queensland, Australia for his critical review.

\section{Authors' contributions}

MRN, KR, AM designed and coordinated the study; NA, ENM, KB, SRM performed the experiments, acquired and analyzed data; HM, AY, MRT, HAA interpreted the data; NA, MRN, KR, AM wrote the manuscript. All authors read and approved the final manuscript.

\section{Funding}

Gastroenterology and Liver Diseases Research Center, Research Institute for Gastroenterology and Liver Diseases, Shahid Beheshti University of Medical Sciences, Tehran, Iran, supported the study.

\section{Availability of data and materials}

All data generated or analyzed during this study are included in this published article. The datasets used and analyzed during the current study are not publicly available due to our center's patient confdentiality policies, but they are stored in the Gastroenterology and Liver Diseases Research Center, Research Institute for Gastroenterology and Liver Diseases, Shahid Beheshti University of Medical Sciences repository and are available from the corresponding author on reasonable request.

\section{Declarations}

\section{Ethics approval and consent to participate}

This study was approved by the Ethics Committee of Shahid Beheshti University of Medical Sciences, Tehran, Iran (IR.SBMU.RETECH.REC.1399.088) and conducted in accordance with the Declaration of Helsinki. All methods were carried out in accordance with relevant guidelines and regulations. All patients signed the informed consent form. Moreover, informed consent was obtained from parents and/or legal guardian for participants under 16 years of age.

\section{Consent for publication}

Not applicable.

\section{Competing interests}

The authors declare that they have no competing interests.

\section{Author details}

${ }^{1}$ Basic and Molecular Epidemiology of Gastrointestinal Disorders Research Center, Research Institute for Gastroenterology and Liver Diseases, Shahid Beheshti University of Medical Sciences, Tehran, Iran. ${ }^{2}$ Foodborne and Waterborne Diseases Research Center, Research Institute for Gastroenterology and Liver Diseases, Shahid Beheshti University of Medical Sciences, Tehran, Iran. ${ }^{3}$ Gastroenterology and Liver Diseases Research Center, Research Institute for Gastroenterology and Liver Diseases, Shahid Beheshti University of Medical Sciences, Tehran, Iran. ${ }^{4}$ Proteomics Research Center, Faculty of Paramedical Sciences, Shahid Beheshti University of Medical Sciences, Tehran, Iran. ${ }^{5}$ Department of Gastroenterology, MidCentral DHB, Palmerston North, New Zealand.

${ }^{6}$ Research Laboratories, Bambino Gesù Children's Hospital-IRCCS, Rome, Italy.

Received: 14 August 2021 Accepted: 7 December 2021

Published online: 11 December 2021

\section{References}

1. Sharma N, Bhatia S, Chunduri V, Kaur S, Sharma S, Kapoor P, et al. Pathogenesis of celiac disease and other gluten related disorders in wheat and strategies for mitigating them. Front Nutr. 2020;7:6.

2. Barker JM, Liu E. Celiac disease: pathophysiology, clinical manifestations, and associated autoimmune conditions. Adv Pediatr. 2008;55:349-65.

3. Antvorskov JC, Fundova P, Buschard K, Funda DP. Dietary gluten alters the balance of pro-inflammatory and anti-inflammatory cytokines in T cells of BALB/c mice. Immunology. 2013;138(1):23-33.

4. Tanaka T, Narazaki M, Kishimoto T. IL-6 in inflammation, immunity, and disease. Cold Spring Harbor Perspect Biol. 2014;6(10):a016295.

5. Barartabar Z, Nikzamir A, Sirati-Sabet M, Aghamohammadi E, Chaleshi V, Rostami Nejad M, et al. The relationship between $174 \mathrm{G} / \mathrm{C}$ and $-572 \mathrm{G} / \mathrm{C}$ of IL-6 gene polymorphisms and susceptibility of celiac disease in the Iranian population. Przeglad Gastroenterol. 2018;13(4):293-8.

6. Abbasifard M, Khorramdelazad $\mathrm{H}$. The bio-mission of interleukin- 6 in the pathogenesis of COVID-19: a brief look at potential therapeutic tactics. Life Sci. 2020;257:118097.

7. Gubernatorova EO, Gorshkova EA, Polinova AI, Drutskaya MS. IL-6: relevance for immunopathology of SARS-CoV-2. Cytokine Growth Factor Rev. 2020;53:13-24.

8. Nasserinejad M, Shojaee S, Ghobakhlou M, Lak E, Eslami P, Pourhoseingholi MA. The effects of IL-8, IL-6, and IL-1 on the risk of celiac disease: a Bayesian regression analysis. Gastroenterol Hepatol Bed Bench. 2019;12(Suppl1):S117-22.

9. Lei H, Schmidt-Bleek K, Dienelt A, Reinke P, Volk H-D. Regulatory T cellmediated anti-inflammatory effects promote successful tissue repair in both indirect and direct manners. Front Pharmacol. 2015;6:184

10. Asri N, Rostami-Nejad M, Barzegar M, Nikzamir A, Rezaei-Tavirani M, Razzaghi M, et al. Suppressive mechanisms induced by tregs in celiac disease. Iran Biomed J. 2020;24(3):140-7.

11. Cavalcanti AB, Zampieri FG, Rosa RG, Azevedo LCP, Veiga VC, Avezum $A$, et al. Hydroxychloroquine with or without Azithromycin in mild-tomoderate Covid-19. N Engl J Med. 2020;383(21):2041-52.

12. Chen Z, John WE. T cell responses in patients with COVID-19. Nat Rev Immunol. 2020;20(9):529-36.

13. Corbett KS, Flynn B, Foulds KE, Francica JR, Boyoglu-Barnum S, Werner $A P$, et al. Evaluation of the mRNA-1273 vaccine against SARS-CoV-2 in nonhuman primates. N Engl J Med. 2020;383(16):1544-55.

14. Singhal T. A review of coronavirus disease-2019 (COVID-19). Indian J Pediatr. 2020;87(4):281-6.

15. Bivona $G$, Agnello L, Ciaccio M. Biomarkers for prognosis and treatment response in COVID-19 patients. Ann Lab Med. 2021;41(6):540-8.

16. Lo Sasso B, Gambino CM, Scichilone N, Giglio RV, Bivona G, Scazzone C, et al. Clinical utility of midregional proadrenomedullin in patients with COVID-19. Labor Med. 2021;52(5):493-8.

17. Felsenstein S, Herbert JA, McNamara PS, Hedrich CM. COVID-19: immunology and treatment options. Clin Immunol. 2020;215:108448. 
18. Nasonov E, Samsonov M. The role of interleukin 6 inhibitors in therapy of severe COVID-19. Biomed Pharmacother Biomed Pharmacother. 2020:131:110698.

19. Grifoni E, Valoriani A, Cei F, Lamanna R, Gelli AMG, Ciambotti B, et al. Interleukin-6 as prognosticator in patients with COVID-19. J Infect. 2020;81(3):452-82.

20. Levin BR, Antia R. Why we don't get sick: the within-host population dynamics of bacterial infections. Science (New York, NY). 2001:292(5519):1112-5.

21. Anghelina D, Zhao J, Trandem K, Perlman S. Role of regulatory T cells in coronavirus-induced acute encephalitis. Virology. 2009;385(2):358-67.

22. Stephen-Victor E, Das M, Karnam A, Pitard B, Gautier JF, Bayry J. Potential of regulatory T-cell-based therapies in the management of severe COVID19. Eur Respir J. 2020;56(3):2002182.

23. Bai $X$, Shi H, Yang M, Wang Y, Sun Z, Xu S. Identification of key genes implicated in the suppressive function of human FOXP3+CD25+CD4+ regulatory $T$ cells through the analysis of time-series data. Mol Med Rep. 2018;17(3):3647-57.

24. Pereira LMS, Gomes STM, Ishak R, Vallinoto ACR. Regulatory T cell and forkhead box protein 3 as modulators of immune homeostasis. Front Immunol. 2017;8:605

25. Plitas G, Rudensky AY. Regulatory T cells: differentiation and function. Cancer Immunol Res. 2016;4(9):721-5.

26. Vignali DA, Collison LW, Workman CJ. How regulatory T cells work. Nat Rev Immunol. 2008;8(7):523-32.

27. Gholam-Mostafaei FS, Yadegar A, Aghdaei HA, Azimirad M, Daryani NE, Zali MR. Anti-TNF containing regimens may be associated with increased risk of Clostridioides difficile infection in patients with underlying inflammatory bowel disease. Curr Res Transl Med. 2020;68(3):125-30.

28. Caminero A, Verdu EF. Celiac disease: should we care about microbes? Am J Physiol Gastrointest Liver Physiol. 2019:317(2):G161-70.

29. Zingone F, D'Odorico A, Lorenzon G, Marsilio I, Farinati F, Savarino EV. Risk of COVID-19 in celiac disease patients. Autoimmun Rev. 2020;19(10):102639.

30. Gokden Y, Hot S, Adas M, Ogutmen Koc D, Atak S, Hot AB. Celiac disease and COVID-19 pandemic: should we worry? Acta Gastro-Enterol Belg. 2020;83(4):517-25.

31. Merad M, Martin JC. Pathological inflammation in patients with COVID19: a key role for monocytes and macrophages. Nat Rev Immunol. 2020;20(6):355-62.

32. Tufan A, Avanoğlu Güler A, Matucci-Cerinic M. COVID-19, immune system response, hyperinflammation and repurposing antirheumatic drugs. Turk J Med Sci. 2020;50(Si-1):620-32.

33. Hardy MY, Tye-Din JA. Coeliac disease: a unique model for investigating broken tolerance in autoimmunity. Clin Transl Immunol. 2016;5(11):e112.

34. Elli L, Barisani D, Vaira V, Bardella MT, Topa M, Vecchi M, et al. How to manage celiac disease and gluten-free diet during the COVID-19 era: proposals from a tertiary referral center in a high-incidence scenario. BMC Gastroenterol. 2020;20(1):387.

35. Costela-Ruiz VJ, Illescas-Montes R, Puerta-Puerta JM, Ruiz C, MelguizoRodríguez L. SARS-CoV-2 infection: the role of cytokines in COVID-19 disease. Cytokine Growth Factor Rev. 2020;54:62-75.

36. Rincon M. Interleukin-6: from an inflammatory marker to a target for inflammatory diseases. Trends Immunol. 2012;33(11):571-7.

37. Velazquez-Salinas L, Verdugo-Rodriguez A, Rodriguez LL, Borca MV. The role of interleukin 6 during viral infections. Front Microbiol. 2019;10:1057.

38. Aziz M, Fatima R, Assaly R. Elevated interleukin-6 and severe COVID-19: a meta-analysis. J Med Virol. 2020;92(11):2283-5.

39. Rostamian A, Ghazanfari T, Arabkheradmand J, Edalatifard M, Ghaffarpour S, Salehi M, et al. Interleukin-6 as a potential predictor of COVID-19 disease severity in hospitalized patients and its association with clinical laboratory routine tests. Immunoregulation. 2020;3:29-36.

40. Liu T, Zhang J, Yang Y, Zhang L, Ma H, Li Z, et al. The potential role of IL-6 in monitoring coronavirus disease 2019. medRxiv. 2020:2020.03.01.20029769.

41. Ouyang W, Kolls JK, Zheng Y. The biological functions of T helper 17 cell effector cytokines in inflammation. Immunity. 2008;28(4):454-67.

42. Romero-Adrián T, Leal-Montiel J, Fernandez G. Celiac disease: participation of cytokines and other factors in the immune response. J Gastrointest Disord Liver Funct. 2015;1:1-6.
43. Perrot L, Hemon M, Busnel JM, Muis-Pistor O, Picard C, Zandotti C, et al. First flare of ACPA-positive rheumatoid arthritis after SARS-CoV-2 infection. Lancet Rheumatol. 2021:3(1):e6-8.

44. Han A, Newell EW, Glanville J, Fernandez-Becker N, Khosla C, Chien $\mathrm{YH}$, et al. Dietary gluten triggers concomitant activation of CD4+ and CD8+ aß T cells and $\gamma \delta T$ cells in celiac disease. Proc Natl Acad Sci U S A. 2013;110(32):13073-8.

45. Vorobjova T, Uibo O, Heilman K, Rägo T, Honkanen J, Vaarala O, et al. Increased FOXP3 expression in small-bowel mucosa of children with coeliac disease and type I diabetes mellitus. Scand J Gastroenterol. 2009;44(4):422-30.

46. Jabri B, Sollid LM. T cells in celiac disease. J Immunol (Baltimore, MD: 1950). 2017;198(8):3005-14

47. Tiittanen $M$, Westerholm-Ormio M, Verkasalo M, Savilahti E, Vaarala O. Infiltration of forkhead box P3-expressing cells in small intestinal mucosa in coeliac disease but not in type 1 diabetes. Clin Exp Immunol. 2008;152(3):498-507.

48. Penttila IA, Gibson CE, Forrest BD, Cummins AG, LaBrooy JT. Lymphocyte activation as measured by interleukin-2 receptor expression to gluten fraction 111 in coeliac disease. Immunol Cell Biol. 1990;68(Pt 3):155-60.

49. Frisullo G, Nociti $V$, lorio R, Patanella AK, Marti A, Assunta B, et al. Increased CD4+CD25+Foxp3+T cells in peripheral blood of celiac disease patients: correlation with dietary treatment. Hum Immunol. 2009;70(6):430-5

50. Boehm F, Martin M, Kesselring R, Schiechl G, Geissler EK, Schlitt HJ, et al. Deletion of Foxp3 + regulatory $T$ cells in genetically targeted mice supports development of intestinal inflammation. BMC Gastroenterol. 2012;12:97

51. Barzaghi F, Passerini L, Bacchetta R. Immune dysregulation, polyendocrinopathy, enteropathy, x-linked syndrome: a paradigm of immunodeficiency with autoimmunity. Front Immunol. 2012;3:211.

52. Wang $Y$, Zheng J, Islam MS, Yang Y, Hu Y, Chen X. The role of CD4(+) FoxP3 $(+)$ regulatory $T$ cells in the immunopathogenesis of COVID-19: implications for treatment. Int J Biol Sci. 2021;17(6):1507-20.

53. Ong EZ, Chan YFZ, Leong WY, Lee NMY, Kalimuddin S, Haja Mohideen SM, et al. A dynamic immune response shapes COVID-19 progression. Cell Host Microbe. 2020;27(6):879-82.e2.

54. Diao B, Wang C, Tan Y, Chen X, Liu Y, Ning L, et al. Reduction and functional exhaustion of T cells in patients with coronavirus disease 2019 (COVID-19). Front Immunol. 2020;11:827.

55. Mohebbi SR, Baghaei K, Rostami-Nejad M, Nazemalhosseini Mojarad E, Mirjalali $\mathrm{H}$, Yadegar A, et al. Significant changes of CD4, FOXP3, CD25, and IL6 expression level in Iranian COVID-19 patients. Gastroenterol Hepatol Bed Bench. 2020;13(4):388-92.

56. Sadeghi A, Tahmasebi S, Mahmood A, Kuznetsova M, Valizadeh H, Taghizadieh A, et al. Th17 and Treg cells function in SARS-CoV2 patients compared with healthy controls. J Cell Physiol. 2021;236(4):2829-39.

\section{Publisher's Note}

Springer Nature remains neutral with regard to jurisdictional claims in published maps and institutional affiliations.

Ready to submit your research? Choose BMC and benefit from:

- fast, convenient online submission

- thorough peer review by experienced researchers in your field

- rapid publication on acceptance

- support for research data, including large and complex data types

- gold Open Access which fosters wider collaboration and increased citations

- maximum visibility for your research: over 100M website views per year

At BMC, research is always in progress.

Learn more biomedcentral.com/submissions 